\title{
Interrelación entre el derecho laboral, derecho de incidencia colectiva y el derecho cooperativo. Estudio de caso
}

(Interrelation between labor law, collective advocacy law and cooperative law. Case study)

\author{
José Alberto Yorg y y Ana María Ramírez Zarza² \\ TECNICOOP (Argentina)
}

Sumario: I. Introducción. II. El Derecho Cooperativo Argentino. III. Abordaje del caso en estudio. IV. Conclusión. V. Bibliografía.

Summary: I. Introduction. II. The Argentine Cooperative Law. III. Approach of the case in study. IV. Conclusion. V. Bibliography

Resumen: En el presente trabajo analizamos un caso que pone su foco, con un método narrativo, interpretativo y reflexivo, sobre acontecimientos de dos docentes cooperativos, maestros de grado, que invocan Derechos Adquiridos en base a situaciones devenidas de la convocatoria realizada desde el Ministerio de Cultura y Educación de la Provincia de Formosa-Argentina — desde el año de 1996 hasta nuestros días-. Se examina la peculariedad de la tensión surgida del trastocamiento del Derecho Constitucional de enseñar y aprender cooperativismo, inescindible al desempeño y la incumbencia profesional de los educadores, como expresión de la doctrina que resalta la relación que hay entre los derechos individuales y sociales, verbigracia. En ese contexto se entrelazan, de manera amigable el Derecho Laboral, el Derecho de incidencia pública y el Derecho Cooperativo.

Palabras clave: Derecho Cooperativo. Derecho laboral. Derecho de Incidencia Colectiva. Educación Cooperativa Escolar.

Abstract: In the present work we analyze a case that puts its focus, with a narrative, interpretive and reflective method, on events of two cooperative teachers, grade teachers, who invoke Acquired Rights based on situations resulting from the call made from the Ministry of Culture and Education of the

1 Profesor. Licenciado en Administración. Especialista en Políticas Socioeducativas. Email: tecnicoop@yahoo.com.ar

2 Profesora. Contadora. Licenciada en Administración. Especialista en Políticas Socioeducativas. Email: tecnicoop@yahoo.com.ar 
Province of Formosa-Argentina - from the year of 1996 to the present day-. It examines the pecularity of the tension arising from the change of the Constitutional Law of teaching and learning cooperativism, inseparable from the performance and professional responsibility of educators, as an expression of the doctrine that highlights the relationship between individual and social rights, for example. In this context, the Law of Public Advocacy and Cooperative Law are interwoven in a friendly manner in Labor Law.

Keywords: Cooperative Law. Labor law. Right of Collective Incidence law. Cooperative School Education. 
«Una cosa no es justa por el hecho de ser ley. Debe ser ley porque es justa» — dijo Montesquieu-. Y nosotros agregamos: «nuestro reclamo de justicia interpela al tribunal».

Jorge Kipper,

«El derecho y la realidad social», Lerner Editores asociados, Buenos Aires (1983), p. 27

\section{Introducción}

Abordamos este tema que conjuga lo jurídico y el cooperativismo, naturalmente corriendo ciertos riesgos en referencia a las precisiones conceptuales que ella exige, dado que no somos abogados, pero que el batallar de tantos años en procura del cumplimiento de los derechos aludidos en el título que el presente artículo fijó, nos da -creemosalguna indulgencia que merezcamos.

El presente estudio y análisis pone su foco en el caso de dos docentes cooperativos, maestros de grado, que invocan derechos adquiridos en base a situaciones devenidas de la convocatoria realizada desde el Ministerio de Cultura y Educación de la Provincia de Formosa desde el año de 1996 hasta nuestros días.

Se examina la peculariedad de la tensión surgida del trastocamiento del derecho constitucional y legal de enseñar y aprender cooperativismo, inescindible al desempeño y la incumbencia profesional de los educadores, como expresión de la doctrina que resalta la relación que hay entre los derechos individuales y sociales, verbigracia, el artículo N. ${ }^{\circ} 2$ de la Ley N. ${ }^{\circ} 26206$, Ley de Educación nacional argentina consagra que "La educación y el conocimiento son un bien público y un derecho personal y social, garantizados por el Estado». En ese contexto se entrelazan, sin contradicción alguna, por el contrario, de manera amigable y complementaria, el Derecho Laboral, el Derecho de incidencia pública y el Derecho Cooperativo, de ello, se demuestra, una vez más, y de manera certera, el carácter distintivo y pertinente del Derecho Cooperativo cual es su dimensión juridica-social, de progreso social-económico, su objetivo de mejoramiento humano.

\section{El Derecho Cooperativo Argentino}

Para comenzar nos valdremos de algunas conceptualizaciones sobre el Derecho Cooperativo Argentino del que se vale el Dr. Alfredo 
Roque Corvalán ${ }^{3}$ en su tesis del Doctorado en Jurisprudencia, Universidad del Salvador, Facultad de Ciencias Jurídicas (1984) «Derecho Cooperativo Argentino: Fundamentos de su autonomía», nos alecciona en la parte Nociones preliminares que el Derecho es un sistema de normas que regula coactivamente conductas humanas, tutela valores y tiende a la coexistencia. ${ }^{4}$

Prosigue, el Derecho Cooperativo, desde sus albores con la sanción en Inglaterra de la Primera Ley de Cooperativas en 1852, ha venido constituyendo un sistema de normas jurídicas que tutela valores fundamentales para lograr y afianzar la coexistencia entre los hombres en base a la justicia social.

Así, la cooperación y la solidaridad han merecido la tutela del Derecho Cooperativo como valores superiores de una escala axiológica - presidida por la justicia - capaces de trasformar un orden económico-social individualista y competitivo por otro solidario y cooperativo.

En síntesis, el Derecho Cooperativo está llamado a normativizar los principios que dan sustento al Sistema Cooperativo como instrumento fundamental para lograr —en paz- un orden económico social más justo, fundado principalmente en el trabajo del hombre. El Derecho Cooperativo Argentino se rige por esos principios

\section{Abordaje del caso en estudio}

Para su mayor precisión y comprensión del caso, en cuanto a que los dos maestros de grado titulares, fueran convocados para realizar otras tareas diferentes que resultaron de mayor responsabilidad y jerarquía de las que desempeñan como docentes primarios, nos da luz la Ley N . 931 «Estatuto del Docente Provincial», en su art. 3 que destaca la situación activa del personal docente señalando dos incisos «a y b», el inciso b) versa de la siguiente manera: "Del personal docente que desempeña otras funciones distintas del cargo para el que fue designado». Aquí es donde encuadran las acciones encomendadas por la cartera educativa a partir de las resoluciones emitidas desde el año citado. El propio Ministerio de Cultura y Educación de la Provincia de Formosa a través de la resolución 511/96 y sucesivas.

Y lo hace la Cartera educativa provincial — convocarlos y asignarles funciones y roles - en virtud a la incumbencia profesional universitaria

3 Conf. : Alfredo Roque Corvalan, «La autonomía del Derecho Cooperativo», LL. Año XLVII, NRO.126(84), p. 3.

4 http://www.codigocivilonline.com.ar/articulo-14/ 
que les otorga el titulo "Técnico en Cooperativismo» y posteriormente Licenciado en Administración alcanzados en la Universidad Nacional de Formosa - UNaF- a que se den a la tarea de la elaboración y puesta en marcha de un Programa de Educación y Desarrollo Cooperativo Escolar, durante todo el periodo que abarca desde el año de 1996 hasta la fecha, reiteramos.

A nuestro modesto criterio,es en este punto de la exposición sobre el meollo de la cuestión que nos acupa, en el que sostenemos que surgen la interrelación entre el derecho laboral, derecho de incidencia colectiva y el derecho cooperativo, puesto que son estos campos del derecho argentino vigente donde se impacta el daño. Daño de carácter individual, colectivo y social.

El artículo n. 1737 del Código Civil y Comercial en el capítulo 1 Responsabilidad Civil-Sección 4. ${ }^{\circ}$ Daño resarsible: Concepto de daño: Hay daño cuando se lesiona un derecho o un interés no reprobado por el ordenamiento jurídico, que tenga por objeto la persona, el patrimonio, o un derecho de incidencia colectiva y el propio derecho cooperativo.

\section{Código Civil y Comercial de la Nación}

(Ley 26.994/ 2014)

Artículo 14. Derechos individuales y de incidencia colectiva. En este Código se reconocen:

a) Derechos individuales;

b) Derechos de incidencia colectiva.

La ley no ampara el ejercicio abusivo de los derechos individuales cuando pueda afectar al ambiente y a los derechos de incidencia colectiva en general.

\section{Clasificación general de los derechos}

De acuerdo a lo establecido en esta norma, el CCyC regula dos tipos de derechos:

a) Los derechos individuales: en este caso el interés es individual, lo que se proyecta en la legitimación, pues los derechos sobre bienes jurídicos individuales deben ser ejercidos por su titular, aun cuando sean varias las personas afectadas.

b) Los derechos de incidencia colectiva: estos pueden ser invocados por sujetos que presentan un interés difuso, colectivo o público. En tal supuesto, el interés jurídico protegido es colectivo, por lo que existe una legitimación activa difusa. 
El punto central pasa por la lesión de intereses, no tan sólo de los docentes cooperativos en sus derechos laborales, profesionales y personales que son menoscabados por el hecho dañoso, sino que desbordan ampliamente estos estrechos muros y abarcan el derecho de incidencia colectiva y el propio derecho cooperativo.

A partir de aquí estableceremos la estrecha vinculación que se establece en este caso en estudio de los derechos laborales, colectivos y cooperativo.

En cuanto al derecho laboral de los docentes que desempeñan funciones técnico-pedagógicas y administrativas reconocidas y avaladas por documentos oficiales, y que éstas fueron labores de mayor jerarquía y responsabilidad.

El hecho y el acto jurídico-administrativo de encomendar la elaboración de un proyecto de Educación y Desarrollo Cooperativo Escolar, para los niveles de Enseñanza General Básica y de Media-polimodal, constituye una labor de mayor jerarquía y responsabilidad que estar frente al aula como maestros. Coordinar los aspectos técnicos-pedagógicos con la Subsecretaria de educación, la Dirección de Planeamiento educativo y la Secretaria Técnica de la Dirección de Educación General Básica, también constituye una labor de mayor jerarquía y responsabilidad. Todo compatible a lo normado en el Estatuto del Docente en su capítulo VI «Disposiciones especiales para el área de Apoyo Técnico, de Planeamiento, las Investigaciones y sus Modalidades como: Analista Mayor Técnico Docente, ley 931-Decreto reglamentario N. 1324/83Capitulo LXXXIII del escalafón (artículo n. ${ }^{\circ} 241$-inc «d»).

Que se entiende que estas asignaciones de responsabilidad técnico-pedagógica y administrativa, como así también de representación Provincial del Cooperativismo Escolar en las que les cupo actuar activamente en eventos de carácter nacional e internacional durante más de diez años, de los cuales se concluye que tales hechos y actos devinieron en hechos y actos jurídicos y como tales, sus efectos jurídicos, dan lugar a situaciones jurídicas consolidadas, y así configurarían en Derecho Adquirido

Por analogía y sostén del principio de subsidiariedad, el artículo 78 de la Ley del contrato de trabajo en general N. ${ }^{\circ} 20.744$ (Deber de ocupación). El empleador deberá garantizar al trabajador ocupación efectiva, de acuerdo a su calificación o categoría profesional, salvo que el incumplimiento responda a motivos fundados que impidan la satisfacción de tal deber. Si el trabajador fuese destinado a tareas superiores, distintas de aquéllas para las que fue contratado tendrá derecho a percibir la remuneración correspondiente por el tiempo de su desempeño, si la asignación fuese de carácter transitorio. 
Se reputarán las nuevas tareas o funciones como definitivas si desaparecieran las causas que dieron lugar a la suplencia, y el trabajador continuase en su desempeño o transcurrieran los plazos que se fijen al efecto en los estatutos profesionales o las convenciones colectivas de trabajo. (texto según ley 21.297)

En el caso en examen el decisor político omitió reconocer administrativamente estas labores de mayor responsabilidad y jerarquía a través de un instrumento resolutorio ministerial como es dable procedimentalmente.

Ahora, esa labor aludida arriba de este párrafo, en conexión con el derecho y garantía constitucional de enseñar y aprender, trascribimos, sintéticamente, cuanto sigue por su valiosa argumentación en pos del derecho de enseñar y aprender y que contiene al derecho de "enseñar y aprender cooperativismo» en base a normativas, tales como, la Ley N. ${ }^{\circ}$ 26. 206 en su artículo N. ${ }^{\circ} 90$, Ley N. ${ }^{\circ} 23427$ «Fondo de educación y promoción cooperativa», Ley N. ${ }^{\circ} 16583$, entre otras.

Alegan los «Alumnos de la Escuela de Educación Media N. ${ }^{\circ} 6$ (Ex Nacional de Vicente López) Vicente López, Provincia de Buenos Aires. (Agustín Álvarez 1427/31 (1638); tel: 47958889)», dirigido: A las máximas autoridades del Gobierno de la Nación Argentina y Provincia de Buenos Aires; A las máximas autoridades Legislativas de la Nación Argentina y Provincia de Buenos Aires; A todos los ciudadanos de la Nación:

«El Derecho a la Educación se encuentra garantizado en nuestra Constitución Nacional en el art. 14 desde el mismo momento en que fue sancionada en el año 1853. Este derecho jamás fue puesto en duda ni fue separado de los preceptos fundamentales que dieron origen a nuestro país como Nación en ninguna de las reformas posteriores.»

«Por el contrario, el Derecho a la Educación conforma, actualmente un derecho que se encuentra reforzado por la incorporación a nuestra C.N. de Convenciones y Tratados Internacionales, plasmados en el art. 75 inc. 22, que hacen al Sistema Internacional de Derechos Humanos.»

"Así el derecho que hoy estamos reclamando nos sea garantizado, en las condiciones que la propia Carta Magna impone». "La Constitución Nacional no es "best seller", que sirve para ratos de ocio de gobernantes y ciudadanos, es nuestro máximo resguardo ante el avasallamiento concreto y/u potencial del sistema de Derechos y Garantías que nos amparan. Cuando decimos "nos amparan", decimos que es el piso del que se parte y del cual no nos podemos bajar.» 
El derecho de enseñar cooperativismo de los docentes cooperativos formoseños está cercenado por los decisores políticos, y como consecuencia directa de ello, el pueblo de Formosa, estamos hablando de niños, jóvenes estudiantes y toda la comunidad, encuentra cercada su derecho de aprender.

Ahondemos más sobre el alcance del Derecho cooperativo, sostenidos con el libro DERECHO COOPERATIVO (2015) de Alvaro Hernan Mejía Mejía:

1. DERECHO COOPERATIVO Concepto General: El derecho cooperativo puede ser entendido como el conjunto de normas y de principios que regulan las relaciones jurídicas que surgen entre las personas y las cooperativas, entre éstas entre sí, y de ellas con el Estado, con ocasión de toda actividad cooperativa encaminada a la producción, distribución y consumo de bienes y servicios.

2. DERECHO COOPERATIVO Concepto Especial (Guarín) Para Guarín (1991) es el conjunto de normas especiales, jurisprudencias, doctrinas y prácticas que determinan, regulan y condicionan las actuaciones de los organismos cooperativos y los sujetos que en ellas participan.

3. DERECHO COOPERATIVO Concepto Especial Henry (2010) dice: «Por derecho cooperativo entiendo todas las reglas jurídicas, así como la práctica jurídica con incidencia en la estructura y/o las operaciones de las cooperativas». Es decir, es el derecho relacionado directamente con la forma jurídica cooperativa, bien sea a nivel de base, de sus organismos de integración y de sus relaciones con el Estado.

Así entonces, las leyes nacionales previamente citadas más arriba como la Ley N. 23427 «Fondo de educación y promoción cooperativa», Ley N. ${ }^{\circ}$ 16583; Ley N. 20 337, Ley N. 26206, artículo N. ${ }^{\circ}$ 90; entre otras, conforman el derecho cooperativo argentino incorporados efectivamente.

Examinemos el fenómeno relacional entre el Estado y el cooperativismo en la esfera educativa, que es, por cierto, una relación peculiar y lo demostraremos.

La Ley N. ${ }^{\circ} 16.583$ y sus decretos reglamentarios declara "de alto interés nacional la enseñanza de los principios del cooperativismo y estableció como obligatoria la enseñanza del cooperativismo y el mutualismo en todos los establecimientos educativos argentinos.

El Fondo para la Educación y Promoción Cooperativa que configura la Ley N. ${ }^{\circ} 23427$ se financia, entre otros recursos, con la contribución 
especial sobre el capital de las cooperativas regularmente constituidas y que se considera una contribución y no de un impuesto.

Dice en el Titulo 1; Artículo 1. ${ }^{\circ}$. Créase el fondo para Educación y Promoción Cooperativa cuyas finalidades serán las siguientes: a) Promover mediante los programas pertinentes la educación cooperativa en todos los niveles de enseñanza primaria, secundaria y terciaria; b) Promover la creación y desarrollo de cooperativas en todos los ciclos del quehacer económico, producción primaria y fabril, comercial, de servicios, vivienda, trabajo y consumo; c) Asesorar a las personas e instituciones sobre los beneficios que otorga la forma cooperativa de asociarse, previstas en la Ley 20.3370 aquella que en el futuro la modifique o sustituya;

Estos fondos, de carácter específico y genino, puesto que provienen de las propias cooperativas son co-participadas con las Provincias mediante leyes de adhesión a las mismas, en el caso de Formosa, lo hizo a través de la Ley N. ${ }^{\circ} 774 / 88$ sólo admiten ese destino y no otro. Garantizan el servicio educativo cooperativo, va de suyo entonces que es de inexcusable cumplimiento para los Estados provinciales y el Estado nacional.

Estas dos leyes del Derecho cooperativo analizadas, de manera rápida pero la entendemos efectiva, constituyen un entramado jurídico por demás interesante con el Estado, sin dudas.

\section{Conclusión}

Por consiguiente, y por lo que sin ninguna duda, queda establecido, a nuestro modesto razonar, la interrelación confluyente de derechos, en lo laboral, de incidencia colectiva y el derecho cooperativo que deben ser respetados y otorgados por justa causa. Se ha establecido lo inédito del caso, su carácter sui generis, por cuanto, la novedad radica en que el derecho laboral que le asiste a los docentes cooperativos, en cuanto a enseñar cooperativismo, tiene anclaje en el derecho de incidencia colectiva de aprender de la comunidad educativa toda, y en el derecho cooperativo, que por cierto, tienen sustancia jurídica en ello.

De ello, se devela, se evidencia, se constata, la confluencia, la convocatoria, a los campos del derecho laboral, de incidencia colectiva y del derecho cooperativo en el caso en estudio.

La demanda interpuesta ante el Superior Tribunal de Justicia de la Provincia de Formosa por los docentes cooperativos en la procura de hacer cejar el daño social que se entiende de "acción continuada» y alcanzar de tal modo el resarcimiento correspondiente para la totalidad de afectados, los colectivos, deviene en una seria interpelación, y de re- 
sultar justiciera, es posible y deseable que sientan jurisprudencia y doctrina sobre la cuestión.

\section{Bibliografía}

ANDER EGG, Exequiel. 1989. Técnicas de investigación social, 21. a edición, Humanitas, Buenos Aires, Argentina.

LAMBERT, Paúl. 1975. La Doctrina Cooperativa. Intercoop Editora Cooperativa Limitada. Cuarta Edición. Bs. As.

LONDOÑO, Carlos Mario. 1976. Movimiento Cooperativo y el Estado, Intercoop Editora Cooperativa Limitada. Bs. As. República Argentina.

SCHUJMAN, L. 1986. La Enseñanza del Cooperativismo en la Educación Pública Idelcoop Buenos Aires. Argentina.

YORG José, RAMÍREZ ZARZA, Ana María, »Propuesta didáctica para la enseñanza del cooperativismo escolar rural».-Portal del Ministerio de Educación Nacional en su capítulo denominado Mapa Educativo Nacional en la especialidad de Educación Rural. www.-mapaeducativo.edu.ar.

CODIGO CIVIL Y COMERCIAL DE LA NACIÓN, Ley 26.994/ 2014.

CONSTITUCIÓN de la República Argentina.

LEY DE COOPERATIVAS 20337.

LEY 23427 y 744 Fondo de Educación y Promoción Cooperativa.

LEY DE EDUCACIÓN NACIONAL N. ${ }^{\circ} 26$ 206/06.

\section{Anexo I}

«Improntas educativas y jurídicas del ProDeCoop-Escolar y del ProDeCoop-Universitario y Políticas públicas. Tensiones».

Indagamos sobre el proceso de la educación cooperativa escolar y universitaria enmarcados en sendos Programas de Educación y Desarrollo Cooperativo (ProDeCoop) ejecutados en la Provincia de Formosa (Arg.). Se examina a lo largo del trabajo-captando continuidades y rupturas-tensiones abiertas. Por José Yorg, el cooperario.

«La ley es tela de araña, y en mi ignorancia lo explico, no la tema el hombre rico, no la tema el que mande, pues la rompe el bicho grande y sólo enrieda a los chicos.

Es la ley como la lluvia, nunca puede ser pareja, el que la aguanta se queja, más el asunto es sencillo, la ley es como el cuchillo, no ofiende a quien lo maneja.

Le suelen llamar espada y el nombre le sienta bien, los que la manejan ven en dónde han de dar el tajo, le cae a quién se halle abajo, y corta sin ver a quién. 
Hay muchos que son doctores, y de su ciencia no dudo, más yo que soy hombre rudo, y aunque de esto poco entiendo diariamente estoy viendo que aplican la del embudo.»

Del Martín Fierro de José Hernández.

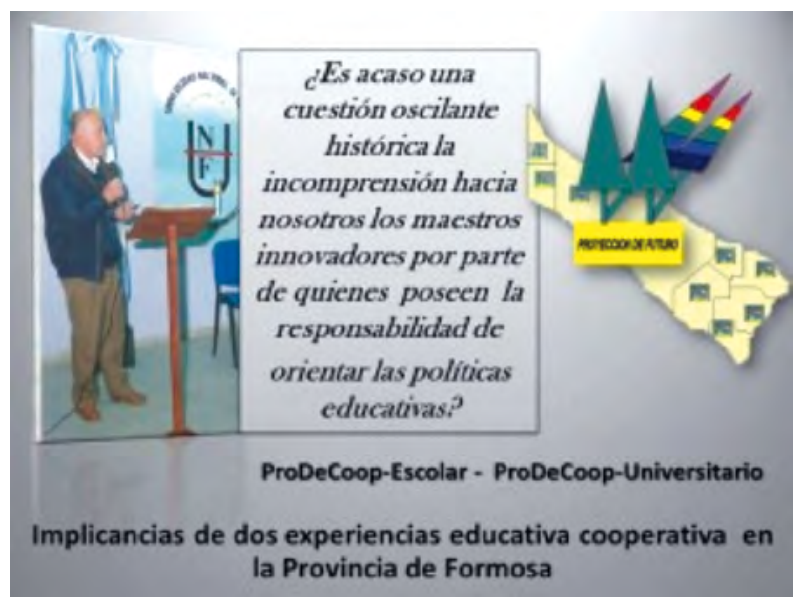

Indagamos sobre el proceso de la Educación Cooperativa Escolar y Universitaria enmarcados en sendos Programas de Educación y Desarrollo Cooperativo (ProDeCoop) ejecutados en la Provincia de Formosa. Se examina a lo largo del trabajo-captando continuidades y rupturas- las políticas públicas, la relación Estado-docentes cooperativos y las tensiones abiertas en ellas.

Partimos de la convicción de que las instituciones o experiencias educativas dejan huellas que marcan improntas en las sociedades. En el presente trabajo se enfoca en las improntas educativas y jurídicas de tales programas, incluyendo a sus actores principales, y que son pasibles de rastreos, por ejemplo, los rasgos distintivos de cada experiencia a partir de indagaciones, recopilación de documentos y testimoniales, como es, sin dudas, este caso.

Precisamente, y a raíz de nuestras indagaciones sobre los orígenes y desarrollo de la educación cooperativa escolar en la Provincia de Formosa, elaboramos y presentamos una ponencia denominada «Historiografía de la educación cooperativa escolar en Formosa, a través de instrumentos oficiales» ante el XXXI Encuentro de Geohistoria Regional que se realizó en la ciudad de Concepción del Uruguay, convocado por Instituto de Historia de la Facultad de Humanidades, Artes y Ciencias 
Sociales (FHAyCS) de la Universidad Autónoma de Entre Ríos (UADER) en el año 2011.

Dicho trabajo se sustentó en normativas legales y experiencias previas singulares bajo las mismas, sus continuidades y rupturas, amalgamando así lo educativo, lo jurídico y políticas públicas sobre las mismas, encuadradas en un proceso de tres etapas desde el año 1971 hasta la fecha.

Lo Jurídico-político. Asumiendo que la normatividad jurídica es producto de decisiones políticas, y que en consecuencia aportan los lineamientos que orientan los procesos educativos en la medida que dan pautas que generan los recorridos, establecen las prioridades y legitiman el quehacer educativo. En este sentido lo jurídico y lo político se constituyen en elementos de la trama que teje lo educativo cooperativo escolar y universitario que incumbe a la comunidad en su conjunto.

Esa conjunción de lo jurídico y educativo se da en posturas asumidas desde el Estado con respecto al cooperativismo, tal como señalan los convocantes del evento: «Esta postura no es novedosa si consideramos la historia de América Latina donde el Estado ha tenido diferentes posturas que van desde la persecución, pasando por la prescindencia, la absorción o la promoción».

El arsenal legal que sustenta la efectiva aplicación de la educación cooperativa y que es de inexcusable cumplimiento por parte del Estado es cuantioso y generoso, dado que se provee de genuinos y específicos fondos económicos-financiero para ello. Huelga citarlos: Leyes N. ${ }^{\circ} 23.427 ; 20.337 ; 16.583 ; 26.206$ en su artículo N. ${ }^{\circ} 90$.

Tales cuestiones se hallan localizadas, tanto, en la constitución nacional, como en la constitución provincial, en lo referente al derecho de aprender y enseñar, amén de otras normativas específicas. Son claramente normativas que implican mandas del Estado y derechos de orden público en tensión.

Tanto es así que esa trama importa también deberes legales contraídas por el Estado para con los docentes cooperativos en tales acciones educativas, jurídicas y políticas, quienes adquirieron responsabilidades y derechos.

Los actos administrativos y educativos desenvueltos -en esfera del ProDeCoop-Escolar y ProDeCoop-Universitario- acreditados en Resoluciones diversas, notificaciones, notas formales, acciones educativas y representativas, etc., importaron Hechos y Actos Jurídicos que configurarían una relación jurídica y laboral de mayor jerarquía entre Estado-Docentes cooperativos, toda vez que los segundos-inicialmente maestros de grados titulares-se graduaron en estudios universitarios y 
desempeñaron en consecuencia roles y funciones de mayor responsabilidad administrativa y educativa.

El ProDeCoop-Escolar germina normativamente bajo la Resolución N. ${ }^{\circ}$ 1892/01 y se defenestra por la Resolución N. ${ }^{\circ}$ 630/07 ambos del Ministerio de Educación de la Provincia de Formosa.

A pesar de la dejación del programa en el año 2007-surge en el mismo ciclo educativo - vinculación jurídica-política y educativa entre el Ministerio de Educación de la Provincia de Formosa y la Universidad Nacional de Formosa-UNaF- que diera inicio y desarrollo al ProDeCoop-Universitario, mediando en ella la formal nota N. ${ }^{\circ}$ 0031/07 emitida por el Rector Ing. Martín Romano solicitando a la cartera educativa «la afectación de los servicios de los Profesores José Yorg, Ana María Ramírez y Juan Velázquez»..., los expertos en cooperativismo, tendrán a su cargo la elaboración y diseño de un Plan de acción que en materia cooperativa pretendemos llevar adelante».

Tal vinculación a la fecha está plenamente vigente en virtud a la Resolución N . 0443/2015 del Ministerio de Educación de la Provincia de Formosa.

La intensa actividad educativa se sintetiza en los cuerpos orgánicos del ProDeCoop-Escolar y del ProDeCoop-Universitario: Diseños Curriculares, diversas ponencias presentadas a nivel nacional e internacional, tesis académicas, conferencias, cursos y talleres, confección de materiales pedagógicos, guiones didácticos en cursos virtuales, amén que ambos programas fueron base y sustento de tesis de grados: "Vinculación entre las Universidades y las Cooperativas de Trabajo», Alejandro Cristaldo y María Florencia Maciel de la carrera de Licenciatura en Administración de la Facultad de Ciencias Económicas de la Universidad Nacional de Rosario, elaborado en el año 2008 en que los autores hacen expresa mención al ProDeCoop-Universitario en la formulación de sus indagaciones en el capítulo III Vinculación entre educación y cooperativas y lo propio en cuanto al ProDeCoop-Escolar en el trabajo académico de Gabriela Silveira de la carrera Diplomatura Superior en Desarrollo Local y Economía Social de la Facultad Latinoamericana de Ciencias Sociales (FLACSO) denominado «Las cooperativas escolares como práctica para la libertad. Una Estrategia de Fortalecimiento del Factor "C», que data de diciembre del 2009. Son sólo unos pocos elementos que reflejan la fecunda acción en esos campos.

Las rupturas del proceso educativo cooperativo escolar y universitario actual en la Provincia de Formosa constituyen un interrogante aún por dilucidar, por tanto, el proceso en tensión se mantiene.

Paradojalmente, interesa destacar que el contexto nacional es óptimo para la actividad educativa cooperativa desde el año 2003 con la 
asunción del Dr. Néstor Kirchner, quien desplegó una clara decisión política a favor de la promoción de las entidades cooperativas.

La Ley de educación nacional N. ${ }^{\circ} 26.206$ en su artículo N. ${ }^{\circ} 90$ sancionada en el año 2006 en que incorporó expresamente al cooperativismo y mutualismo escolar constituye un formidable impulso al desarrollo de esta modalidad educativa.

En el evento universitario en que se aportará este trabajo «debatiremos el rol del Estado y de la Universidad a partir de la trayectoria de las políticas públicas intentando dar cuenta de la toma de su posición y de qué manera ésta influyó en el desarrollo del cooperativismo».

En esa dirección, la Secretaría de Políticas Universitarias-SPU —-dependiente del Ministerio de Educación de la Nación- creó en el año 2013 por medio de la Resolución N. ${ }^{\circ}$ 227/13 SPU el «Programa de Educación Cooperativa y Economía Social en la Universidad». En el presente mes y año, por medio de la Resolución N. ${ }^{\circ} 1615$, el Secretario de Políticas Universitarias, el Dr. Aldo Caballero convocó por segunda vez a las Universidades a la presentación de proyectos de investigación aplicada sobre cooperativismo y economía social, precisando que se priorizarán aquellos proyectos que cuenten con la participación directa de cooperativas». 


\section{Derechos de autor}

El Boletín de la Asociación Internacional de Derecho Cooperativo es una revista de acceso abierto lo que significa que es de libre acceso en su integridad inmediatamente después de la publicación de cada número. Se permite su lectura, la búsqueda, descarga, distribución y reutilización legal en cualquier tipo de soporte sólo para fines no comerciales y según lo previsto por la ley; sin la previa autorización de la Editorial (Universidad de Deusto) o el autor, siempre que la obra original sea debidamente citada (número, año, páginas y DOI si procede) y cualquier cambio en el original esté claramente indicado.

\section{Copyright}

The International Association of Cooperative Law Journal is an Open Access journal which means that it is free for full and immediate access, reading, search, download, distribution, and lawful reuse in any medium only for non-commercial purposes, without prior permission from the Publisher or the author; provided the original work is properly cited and any changes to the original are clearly indicated. 